\title{
An Estuarine Neritid Gastropod, Clithon corona, a Potential Reservoir of Thermostable Direct Hemolysin-Producing Vibrio parahaemolyticus
}

\author{
Aiyamperumal VELAMMAL ${ }^{1)}$, Mina KATO ${ }^{1)}$, Sayaka MIYAGI ${ }^{1)}$, Megumi TOYOZATO ${ }^{1)}$ and \\ Norichika H. KUMAZAWA ${ }^{1) *}$ \\ ${ }^{1)}$ Tropical Biosphere Research Center, University of the Ryukyus, 1 Senbaru, Nishihara, Okinawa 903-0213, Japan
}

(Received 21 December 2004/Accepted 27 April 2005)

ABSTRACT. An estuarine neritid gastropod, Clithon corona, maintained in UV-irradiated recirculating artificial seawater with a salinity of 15 per mil (\%) was found to retain thermostable direct hemolysin (TDH)-producing Vibrio parahaemolyticus in the gut at significantly higher levels than TDH-non-producing one for at least 14 days. Another estuarine neritid gastropod, C. sowerbianus, was not able to support the preferential survival of TDH-producing organisms. This evidence suggests that, if TDH-producing vibrios are brought to estuaries inhabited by $C$. corona, repeated ingestion of $V$. parahaemolyticus by this gastropod could lead to accumulation of TDH-producing vibrios in the estuaries.

KEY WORDS: Clithon corona, reservoir, $V$. parahaemolyticus.

J. Vet. Med. Sci. 67(8): 833-835, 2005

Vibrio parahaemolyticus is an autochthonous estuarine organism that can cause gastroenteritis in man after consumption of contaminated raw fish and shellfish $[1,5,8] . \mathrm{V}$. parahaemolyticus was detected in its highest level, $10^{4}-10^{5}$ colony forming units (cfu)/g, in Clithon retropictus (neritid gastropod), attached-microalgae and muddy sediments of Hashizu and Sada Estuaries in Japan [3, 5]. Thermostable direct hemolysin (TDH)-producing (enteropathogenic) vibrios were found to be approximately $20 \%$ of $\mathrm{V}$. parahaemolyticus organisms isolated from $C$. retropictus at Hashizu Estuary, though the occurrence in muddy sediments and water there was $12 \%$ and $1 \%$, respectively [5]. Another field survey at Sada Estuary found that TDH-producing vibrios grew in the gut of juvenile $C$. retropictus from a non-detectable level to $2.0 \times 10^{3} \mathrm{cfu} / \mathrm{g}$ (approximately $15 \%$ of $V$. parahaemolyticus organisms) in a twomonth period between July and September 1991 [3]. TDHproducing vibrios survived at a level of $10^{4}-10^{5} \mathrm{cfu} / \mathrm{g}$ maintained in UV-irradiated recirculating artificial seawater with a salinity of $20 \%$, while TDH-non-producing (non-pathogenic) vibrios survived there at a level of only $10^{1}-10^{2} \mathrm{cfu} /$ g [7]. V. parahaemolyticus can attach to estuarine diatom algae, Navicula spp. regardless of TDH-productivity [2]. This evidence suggests that $V$. parahaemolyticus would overwinter in muddy sediments at estuaries, grow there with rising water temperature, be released into the water column and attach to diatom algae, where it would be ingested by juvenile $C$. retropictus, thereby supporting selective growth of TDH-producing vibrios in the gut.

The range of $C$. retropictus includes many estuaries of the main land of Southern Japan [6], though $V$. parahaemolyticus-gastroenteritis has been reported throughout the world including Southeast Asia [8]. Two neritid gastropods, $C$.

\footnotetext{
* Correspondence to: Prof. Kumazawa, N. H., Tropical Biosphere Research Center, University of the Ryukyus, Okinawa 9030213, Japan.
}

corona and C. sowerbianus, predominate in the estuaries of the Southwest Islands (subtropical zone) of Japan, where $C$. retropictus seems to take refuge in freshwater areas above estuaries in competition with these gastropods [10]. A halophile, $V$. parahaemolyticus, could not survive in the gut of $C$. retropictus which inhabits freshwater areas. This raises the possibility that $C$. corona and $C$. sowerbianus are the reservoirs for TDH-producing strains of $V$. parahaemolyticus in the estuaries of tropical and sub-tropical zones.

In the present study, two TDH-producing and two TDHnon-producing strains of $V$. parahaemolyticus were investigated. The TDH-producing strains, D5 (O3:K6) and D12 $(\mathrm{O} 3: \mathrm{K} 6)$, are nalidixic acid-resistant derivatives of clinical strains, while TDH-non-producing strains, R15 (O8:K41) and R13 (untypable), are rifampicin-resistant derivatives of environmental strains. The bacteria were grown overnight in Heart Infusion Broth (Eiken) supplemented with 3\% $\mathrm{NaCl}$ at $37^{\circ} \mathrm{C}$, washed with artificial seawater (ASW) [7] with a salinity of $35 \%$, and resuspended at $10^{6} \mathrm{cfu} / \mathrm{m} l$ in ASW.

The two neritid gastropods, $C$. corona and C. sowerbianus, were collected from Benoki and Ohura rivers in Okinawa, Japan. Adult and juvenile specimens, 9-13 $\mathrm{mm}$ and 5-7 mm in shell height, respectively, were cleansed of halophilic organisms of the gut by placement in recirculating freshwater at room temperature for one week. They were then kept in ASW with test salinities of 15 and $25 \%$ or $C$. corona and $C$. sowerbianus, respectively, for one week to acclimatize them to the salinities of their natural habitats.

Fifty adults or 120 juvenile gastropods were incubated in ASW containing $10^{6} \mathrm{cfu} / \mathrm{m} l$ of four $V$. parahaemolyticus strains. After $24 \mathrm{hr}$, the gastropods were washed with distilled water and maintained in UV-irradiated recirculating $\mathrm{ASW}$ at $28^{\circ} \mathrm{C}$. They were fed on diatom algae grown on concrete blocks or stones. Five adults and 15 juveniles were sacrificed at appropriate time intervals and the guts attached 


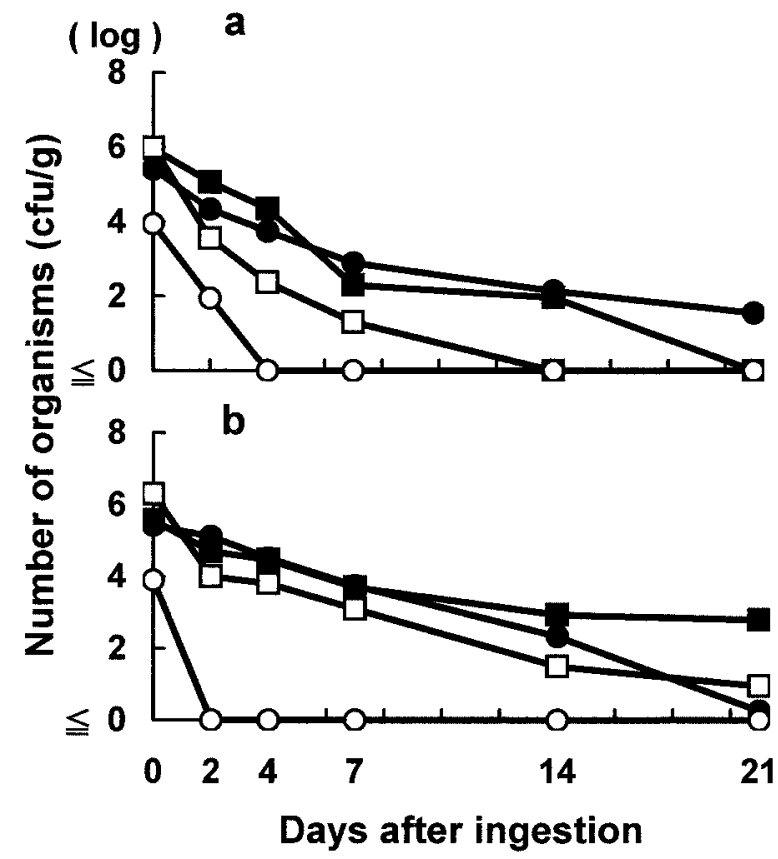

Fig. 1. Survival of $V$. parahaemolyticus strains D5 (-), D12 ), R13 (O) and R15 ( $\square$ ) in juvenile (a) and adult (b) $C$. corona with a salinity of $15 \%$ at $28^{\circ} \mathrm{C}$.

to mid-gut glands were homogenized in sterilized 35\% ASW with a Polytron PT3000 (Kinematica, Switzerland). Viable counts of the homogenates were estimated on Bromothymol Blue Lactose Agar (Eiken) plates supplemented with $5 \% \mathrm{NaCl}$ and $5 \mu \mathrm{g} / \mathrm{m} l$ of appropriate selective drugs. Experiments were repeated three times and the results are presented as a geometric mean. Statistical significance was determined by T-test (SAS system for Windows V8).

TDH-producing strains, D5 and D12, survived at a level of $10^{2} \mathrm{cfu} / \mathrm{g}$ or higher for at least 14 days in the gut of juvenile and adult $C$. corona, while TDH-non-producing strains R13 and R15 exhibited early decrease in survival (Figs. 1a and $1 \mathrm{~b}$ ). Levels of the TDH-producing strains were significantly higher than those of TDH-non-producing strains both in juveniles $(\mathrm{P}<0.01)$ and adults $(\mathrm{P}<0.01)$, upon removal of day 0 data and low-reliability data of $10^{\circ} \mathrm{cfu} / \mathrm{g}$ or less. The results show that TDH-producing strains, via repeated passages through the gut of $C$. corona, could accumulate in estuaries containing this gastropod.

Levels of the test strains decreased gradually and reached $10^{1} \mathrm{cfu} / \mathrm{g}$ or lower on day 14 in the gut of juvenile and adult C. sowerbianus (Figs. $2 \mathrm{a}$ and $2 \mathrm{~b}$ ), indicating the lack of selective survival of TDH-producing strains in the gut of $C$. sowerbianus.

$V$. parahaemolyticus strains were not detected from tank water from the second day of the experiments onward (data not shown), indicating that UV-irradiation eliminated the possibility of the gastropods to re-ingest $V$. parahaemolyticus.

The variable levels of the survival of these strains in gas-

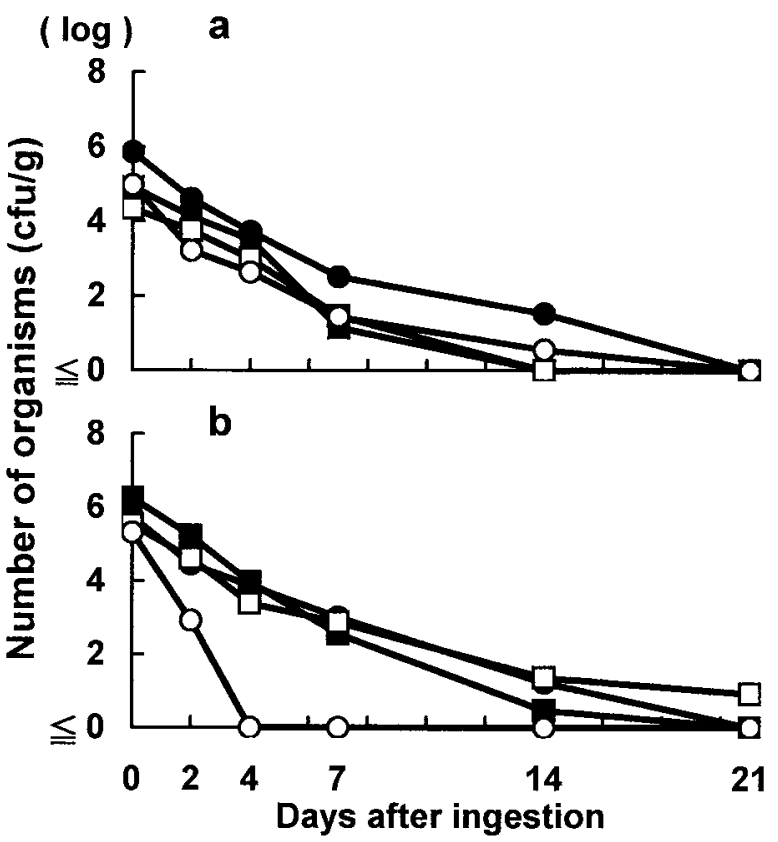

Fig. 2. Survival of $V$. parahaemolyticus strains D5 (), D12 $(\square), \mathrm{R} 13(\mathrm{O})$ and R15 ( $\square$ ) in juvenile (a) and adult (b) C. sowerbianus with a salinity of $25 \%$ at $28^{\circ} \mathrm{C}$.

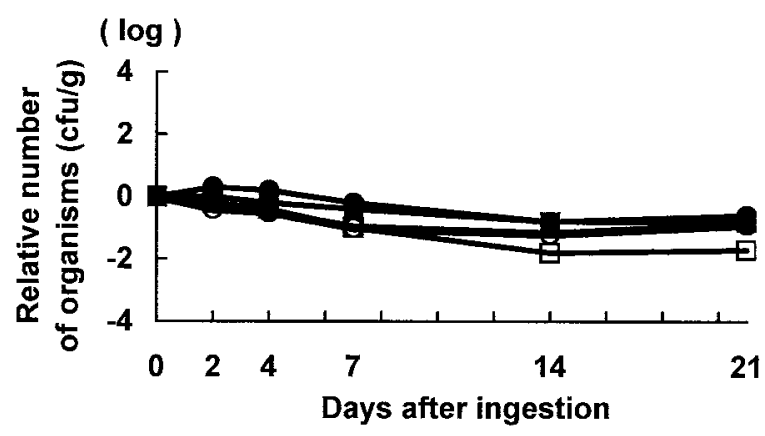

Fig. 3. Survival of $V$. parahaemolyticus strains D5 (O), D12 ), R13 (O) and R15 ( $\square$ ) in ASW with a salinity of $15 \%$ at $28^{\circ} \mathrm{C}$. Levels of the organism are shown as relative number in order to compare the viability of the four strains in ASW.

tropods were concluded to be the results of interaction between $V$. parahaemolyticus strains and these gastropods, since in non-UV-irradiated $15 \%$ ASW $\left(28^{\circ} \mathrm{C}\right) \mathrm{V}$. parahaemolyticus strains were confirmed to survive in a similar numbers for at least 21 days (Fig. 3).

TDH-producing strains were found to survive in the gut of C. corona at significantly higher levels than TDH-nonproducing strains (Fig. 1), suggesting that TDH-producing strains would accumulate in estuaries where C. corona resides, through repeated passages of the strains in the gut of C. corona. In our previous studies, a TDH-producing strain, D3, was found to survive in the gut of a juvenile estuarine neritid gastropod, C. retropictus, at a level 100 times higher than TDH-non-producing strain R13 [7]. Based on this evi- 
dence, TDH-producing strains were suspected to accumulate in estuaries containing juvenile $C$. retropictus [7]. In fact, TDH-producing strains were approximately $20 \%$ of $V$. parahaemolyticus organisms detected in juvenile $C$. retropictus in our field survey at Hashizu Estuary, though the rates in muddy sediment and water there were approximately 12 and $1 \%$, respectively [5]. In estuaries, $C$. corona seems to accumulate TDH-producing strains in a manner similar to that by juvenile $C$. retropictus. TDH-producing strains grown in estuaries could flow out to the sea and contaminate fishing ports or fishing farms near the estuaries.

TDH-producing and TDH-non-producing organisms were eliminated slowly from another estuarine neritid gastropod, C. sowerbianus (Fig. 2), while the marine neritid gastropods, Nerita albicilla and Heminerita japonica, have been shown to eliminate $V$. parahaemolyticus strains within 7 days after ingestion $[4,6]$. Thus, $C$. sowerbianus seems to retain $V$. parahaemolyticus strains for a longer period than marine neritid gastropods do even if they have no ability to accumulate TDH-producing vibrios. In our present study, gastropods were inhibited from re-ingesting excreted $V$. parahaemolyticus by UV-irradiation of the recirculating water. At estuaries where $C$. sowerbianus could repeatedly ingest $V$. parahaemolyticus strains, it appears that $C$. sowerbianus would retain $V$. parahaemolyticus organisms. The reason estuarine neritid gastropods are able to retain TDHproducing strains could not be explained in the present study. It might be related to the fact that $V$. parahaemolyticus is an estuarine organism. Estuarine invertebrates are likely to evolve to co-exist with other estuarine organisms, including $V$. parahaemolyticus. Such interactions may, over the long-term, have resulted in adaptation of TDH-producing organisms to survive in the gut of estuarine invertebrates.

Prior to the present study, estuarine neritid gastropods were found to retain TDH-producing vibrios at similar levels to or at higher levels than TDH-non-producing ones. Neritid gastropods able to preserve TDH-producing strains at lower levels than TDH-non-producing strains have not yet been found, suggesting that TDH or the related molecule from $V$. parahaemolyticus seems to contribute to colonization in the gut of the gastropods. Mechanisms of the colonization will be investigated in the near future.

C. corona and C. sowerbianus are the dominant neritid gastropods in many estuaries of tropical and subtropical areas in East Asia including the Southwest Islands of Japan. Our data indicate that C. corona would be an important reservoir of TDH-producing vibrios in estuaries it inhabits.

\section{REFERENCES}

1. Kumazawa, N.H. 1989. Food Sanitation Res. 39: 27-33 (in Japanese).

2. Kumazawa, N.H., Fukuma, N. and Komoda, Y. 1991. J. Vet. Med. Sci. 53: 201-205.

3. Kumazawa, N.H., Ikura, K. and Kawasaki, Y. 1996. J. Vet. Med. Sci. 58: 921-923.

4. Kumazawa, N.H., Iwao, K. and Kato, E. 1991. J. Vet. Med. Sci. 53: 69-71.

5. Kumazawa, N.H. and Kato, E. 1985. J. Hyg. Camb. 95: 299 307.

6. Kumazawa, N.H., Kato, E., Takaba, T. and Yokota, T. 1988. Jpn. J. Vet. Sci. 50: 918-924.

7. Kumazawa, N.H. and Kawasaki, Y. 1997. J. Vet. Med. Sci. 59: 277-279.

8. Miwatani, T. and Takeda, Y. 1976. pp. 22-45. In: Vibrio parahaemolyticus: A Causative Bacterium of Food Poisoning. Saikon Publishing, Tokyo.

9. Nishiwaki, S., Hirata, T., Ueda, H., Tsuchiya, Y. and Sato, T. 1991. Venus Jpn. J. Malacol. 50: 202-210.

10. Okuda, N. and Nishihira, M. 2002. Benthos Res. 57: 31-44. 